\title{
Pengaruh Komposisi Media Tanam Dan Dosis Npk Terhadap Pertumbuhan Bibit Kopi Robusta (Coffea chanephora L.)
}

\section{Effect Of Planting Media Composition And Npk Dosage On Seedling Growth Of Robusta Coffee (Coffea chanephora L.)}

\author{
Rika Rafita Sari' ${ }^{1}$, Ainun Marliah ${ }^{2}$, Agam Ihsan Hereri' ${ }^{2}$ \\ 1) Alumni Program Studi Agroteknologi Fakultas Pertanian Unsyiah \\ 2) Dosen Program Studi Agroteknologi Fakultas Pertanian Unsyiah \\ Jl. Tgk. Hasan Krueng Kalee No.3, Kopelma Darussalam, Syiah Kuala, Kota Banda Aceh 23111 \\ Email: rikarafita444@gmail.com
}

\begin{abstract}
This study aims to determine the effect of the composition of the planting medium and dosage of NPK which can increase the growth of coffee seedlings. The study were carried out in Lampanah Ranjo, Indrapuri, Aceh Besar from May to September 2018. This study used a Fakorial Block Design (RBD) $4 \times 4$ with 3 replication. The first factor was the planting medium composition (soil : manure) consist of 4 level control $\left(K_{0}\right), 1: 1\left(K_{1}\right), 1: 2\left(K_{2}\right), 2: 1\left(K_{3}\right)$. The second factor was NPK dosage consist of 4 level control $\left(N_{0}\right), 1 \mathrm{~g} /$ polybag $\left(N_{1}\right), 1,5 \mathrm{~g} /$ polybag $\left(N_{2}\right), 2 \mathrm{~g} /$ polybag $\left(N_{3}\right)$. The data were obtained and analyzed using the $F$ test, followed by BNJ test at the level of 5\%. The result of this study indicate that the treatment of the planting medium composition has a very significant effect on the parameter of stem diameter on 60,90 DAP, dry strover weight and root volume mean while the significant effect on the parameter of stem diameter on $30 \mathrm{DAP}$ and wet stover weight. The best planting medium composition was 2:1. The treatment of NPK dosage has a very significant effect on the parameters of seedling height 30 $D A P$, wet stover weight and dry stover weight. The NPK dosage of 1,5/polybag tend to be best treatment. There is a real interaction between the planting medium composition and NPK dose to the parameters of the stem diameter of $30 \mathrm{DAP}$ and the weight of the wet stover and has a significant effect on the parameters of dry stover weight. The growth of coffee seedlings is best found in a combination of 2: 1 planting media composition with a dose of NPK $1.5 \mathrm{~g} /$ polybag.
\end{abstract}

Keyword: Coffee, planting media, fertilizer

\begin{abstract}
ABSTRAK
Penelitian ini bertujuan untuk mengetahui pengaruh komposisi media tanam dan dosis NPK terhadap pertumbuhan bibit kopi. Penelitian dilaksanakan di Gampong Lampanah Ranjo, Kecamatan Indrapuri Kabupaten Aceh Besar dari bulan Mei sampai bulan September 2018. Penelitian ini menggunakan Rancangan Acak Kelompok (RAK) pola faktorial 4 x 4 dengan 3 ulangan. Faktor pertama yaitu komposisi media tanam (tanah : pupuk kandang) terdiri dari 4 taraf yaitu kontrol $\left(\mathrm{K}_{0}\right)$, 1:1 $\left(\mathrm{K}_{1}\right), 1: 2\left(\mathrm{~K}_{2}\right), 2: 1\left(\mathrm{~K}_{3}\right)$ dan faktor kedua dosis NPK terdiri dari 4 taraf kontrol $\left(\mathrm{N}_{0}\right), 1 \mathrm{~g} /$ polibag $\left(\mathrm{N}_{1}\right), 1,5 \mathrm{~g} /$ polibag $\left(\mathrm{N}_{2}\right), 2 \mathrm{~g} /$ polibag $\left(\mathrm{N}_{3}\right)$. Data yang diperoleh dianalisis menggunakan uji $\mathrm{F}$, dilanjutkan dengan uji BNJ pada taraf 5\%. Hasil penelitian
\end{abstract}


menunjukkan bahwa perlakuan komposisi media tanam berpengaruh sangat nyata pada parameter diameter batang 60, 90 hari setelah tanam (HST), bobot brangkasan kering dan volume akar serta berpengaruh nyata pada parameter diameter batang 30 HST dan bobot brangkasan basah. Komposisi media tanam terbaik dijumpai pada komposisi media tanam dengan prbandingan tanah : pupuk kandang (2:1). Perlakuan dosis NPK berpengaruh sangat nyata terhadap parameter tinggi bibit $30 \mathrm{HST}$, bobot brangkasan basah dan bobot brangkasan kering. Dosis NPK lebih baik dijumpai pada dosis NPK 1,5 g/polibag. Terdapat interaksi yang sangat nyata antara komposisi media tanam dan dosis NPK terhadap parameter diameter batang 30 HST dan bobot brangkasan basah serta berpengaruh nyata terhadap parameter bobot brangkasan kering. Pertumbuhan bibit kopi terbaik dijumpai pada kombinasi komposisi media tanam 2:1 dengan dosis NPK 1,5 g/polibag.

Kata kunci : Kopi, media tanam, pupuk

\section{PENDAHULUAN}

Sebagai salah satu negara penghasil kopi terbesar di dunia setelah kolombia, brazil dan Vietnam, produksi kopi di Indonesia mencapai 600.000 ton per tahun dimana lebih dari $80 \%$ dihasilkan dari perkebunan yang dikelola rakyat. Kopi menempati posisi ke empat setelah kayu, karet dan kelapa sawit sebagai penghasil devisa dari ekspor komoditi pertanian yang tinggi dalam perekonomian Indonesia. Kopi dapat digunakan sebagai bahan baku industri makanan, minuman dan kosmetik (Pertiwi dan Ardian, 2016).

\footnotetext{
Data Statistik Perkebunan Indonesia (Ditjen Perkebunan, 2015-2017), menyajikan data produksi kopi sebesar 639.412 ton pada tahun 2015 yang berasal dari 1.230.001 ha dari luas areal perkebunan kopi sebanyak 96\% merupakan perkebunan rakyat (PR) dan sisanya dihasilkan oleh perkebunan swasta (PBS) dan perkebunan besar milik negara (PBN) sebanyak $2 \%$. Produksi kopi nasional pada tahun 2016 mencapai 639.305 ton menurun dari tahun 2015. Pada 2017 produksi kopi mencapai 637.539 ton yang berarti kembali turun 0,28\% dari tahun 2017 .
}

Permasalahan yang muncul yaitu masih rendahnya produktivitas kopi dalam pengusahaan kopi di Indonesia, agar dapat meningkatkan produktivitas dapat dilakukan dari proses pembibitan yang sangat penting bagi pertumbuhan kopi. Bibit yang baik akan menghasilkan buah kopi yang banyak. Agar mendapatkan hasil produktivitas kopi yang maksimal selama masa pembibitan media tanam dan pemupukan harus diperhatikan (Dewantara et al., 2017).

Menurut
Prayugo
menyatakan bahwa media tanam adalah
tempat tumbuhnya tanaman yang memiliki
fungsi mampu mengikat air, dapat
menyediakan unsur hara bagi kebutuhan
tanaman, menjaga air yang berlebihan,
menjaga sirkulasi dan aerasi tanah serta
menjaga kelembaban pada bagian akar agar
tidak mudah lapuk.

Pemupukan merupakan salah satu cara untuk menjaga ketersediaan unsur hara. Pupuk yang diberikan pada masa pembibitan ada dua jenis yaitu pupuk organik dan pupuk anorganik. Pupuk organik merupakan pupuk bagian dari alam sisa-sisa organisme yang hidup, sisa tanaman ataupun sisa bagian dari hewan yang telah terurai. Pupuk organik mengandung unsur hara mikro dan makro yang dibutuhkan oleh tanaman pada masa 
pertumbuhan. Pupuk kandang, pupuk hijau, kompos dan pupuk guano merupakn beberapa jenis pupuk organic (Handayani et al., 2011).

Salah satu contoh dari pupuk kandang adalah pupuk kandang sapi yang dapat memberikan banyak keuntungan bagi pertumbuhan tanaman. Selain itu dengan adanya pemberian pupuk kandang sapi dapat meningkatkan kemapuan tanah dalam menyimpan air yang berfungsi sebagai pelarut bahan organik menjadi unsure hara yang dapat diserap langsung oleh tanaman pada masa pertumbuhan. Air juga berfungsi sebagai media dalam menyerap unsur hara yang terdapat dalam tanah dan akan di distribusikan ke semua bagian tanaman (Sudarto et al., 2003).

Pada pembibitan kopi perkebunan media tanam yang digunakan pada umumnya menggunkan bahan selain tanah, pada pembibitan kopi media tanam yang baik digunakan adalah campuran tanah topsoil, pasir dan pupuk kandang dengan perbandingan 1:1:1 jika tanah sudah remah maka tidak perlu penambahan pasir pada media tanam pembibitan (Rahardjo, 2013).

Menurut Ding (2015), pada komposisi campuran media tanam : pupuk kandang 1:1 menghasilkan tinggi bibit durian sebesar 43,13 cm, diameter bibit 4,60 $\mathrm{mm}$ dan jumlah daun sebesar 11 helai yang nyata lebih banyak dibandingkan dengan perlakuan lainnya pada umur 90 HST. Komposisi media tanam campuran tanah : pupuk kandang sapi menghasilkan perakaran tanaman kopi lebih baik dan akar berkembang sempurna.

Menurut Simorangkir et al. (2016), komposisi media tanam top soil dan pupuk kandang sapi dengan perbandingan 1:2 menghasilkan rataan bobot basah tajuk bibit kakao tertinggi sebesar 33,55 g dan bobot kering tajuk sebesar 18,70 g dibandingkan dengan komposisi media tanam lainnya.

Pupuk anorganik memiliki unsur yang paling dominan dijumpai yaitu unsur N, P dan K. Pemberian pupuk NPK memberikan pengaruh yang baik pada kandungan hara dan tanaman karena adanya unsur hara makro yang dapat membantu dalam masa pertumbuhan tanaman (Sutejo, 2002). Menurut Lingga dan Marsono (2001), salah satu jenis pupuk NPK adalah NPK majemuk Phonska. Kelebihan dari pupuk NPK Phonska adalah merangsang pertumbuhan tanaman khususnya batang.

Menurut Minarsih et al.(2013), pemberian pupuk majemuk NPK dengan dosis sebanyak 1,5 g/tanaman ukuran polibag $15 \mathrm{~cm}$ x $20 \mathrm{~cm}$ berpengaruh nyata terhadap bobot kering tajuk tanaman kakao sebesar 2,7 g, bobot kering akar 1,03 g, bobot basah akar 5,7 g, jumlah daun 17,3 helai dibandingkan dosis lainnya.

Penelitian ini bertujuan untuk mengetahui pengaruh komposisi media tanam dan dosis NPK terhadap pertumbuhan bibit kopi.

\section{BAHAN DAN METODE}

Penelitian telah dilaksanakan di Gampong Lampanah Ranjo, Kecamatan Indrapuri Kabupaten Aceh Besar. Penelitian dilaksanakan pada bulan Mei sampai September 2018.

Bahan yang digunakan dalam penelitian ini adalah biji kopi robusta yang berasal dari buah kopi yang telah berwarna merah, bernas dan sehat, polibag ukuran 15 $\mathrm{cm}$ x $20 \mathrm{~cm}$ atau berkapasitas setara dengan volume $1 \mathrm{~kg}$ tanah top soil, sebanyak 144 lembar, tanah top soil berasal dari Jantho sebanyak $90 \mathrm{~kg}$, pupuk kandang (sapi) sebanyak $54 \mathrm{~kg}$, pupuk NPK Phonska 
(15:15:15) sebanyak $162 \mathrm{~g}$. Untuk tindakan preventif dari gangguan organisma pengganggu tanaman kopi, digunakan insektisida Lannate 25WP dengan dosis $1 \mathrm{~g}$ /liter air dan fungisida Antracol 70WP dengan dosis $1 \mathrm{~g}$ /liter air. Bahan-bahan ini yang diperoleh dari toko pertanian di Lambaro, Aceh Besar. Air yang digunakan selama pemeliharaan tanaman adalah air sumur. Alat yang digunakan dalam penelitian ini adalah timbangan digital dengan ketelitian $0,01 \mathrm{~g}$, meteran pita (dengan ketelitian $0,1 \mathrm{~cm}$ ), jangka sorong (dengan ketelitian $0,1 \mathrm{~mm}$ ), ayakan untuk tanah dengan ukuran 8 mesh, gunting, penggaris, kertas label, sarung tangan, cangkul, ember, gembor, alat tulis dan berbagai peralatan lainnya yang dibutuhkan dalam penelitian ini.

Penelitian ini menggunakan Rancangan Acak Kelompok (RAK) pola faktorial $4 \times 4$ dengan 3 ulangan. Terdapat dua faktor yang diteliti yaitu komposisi media tanam $(\mathrm{K})$ dan dosis pupuk NPK $(\mathrm{N})$. Faktor komposisi media tanam (K) tanah : pupuk kandang yang terdiri dari 4 taraf yaitu: kontrol $\left(\mathrm{K}_{0}\right), 1: 1\left(\mathrm{~K}_{1}\right), 1: 2\left(\mathrm{~K}_{2}\right), 2: 1$ $\left(\mathrm{K}_{3}\right)$. Faktor dosis pupuk NPK $(\mathrm{N})$ yang terdiri dari 4 taraf yaitu: kontrol $\left(\mathrm{N}_{0}\right), 1$ g/polibag $\left(\mathrm{N}_{1}\right), \quad 1,5$ g/polibag $\left(\mathrm{N}_{2}\right), \quad 2$ g/polibag $\left(\mathrm{N}_{3}\right)$. Kombinasi 2 faktor dengan masing-masing 4 taraf perlakuan, diperoleh $4 \times 4=16$ kombinasi perlakuan, dimana masing-masing kombinasi perlakuan diulang sebanyak tiga kali, sehingga terdapat 48 satuan percobaan. Setiap satuan percobaan terdapat 3 unit bibit tanaman sehingga diperoleh 144 unit tanaman. Data hasil penelitian akan dianalisis menggunakan ANOVA. Apabila hasil uji F (Tabel Anova), menunjukkan pengaruh nyata $(\alpha=5 \%)$, maka akan dilanjutkan uji antar rata-rata perlakuan menggunakan prosedur uji lanjut Uji Beda Nyata Jujur (BNJ) pada taraf 5\%.
Benih kopi yang digunakan merupakan benih kopi Robusta. Benih kopi diperoleh dari Pakpak Bharat, Sumatera Utara. Benih kopi yang disiapkan sebanyak 144 butir benih. Benih kopi berasal dari buah kopi terpilih yang telah dikupas dari kulit tanduk dan direndam dengan air selama 48 jam. Benih kopi yang telah direndam kemudian disemai pada polibag kecil. Polibag diisi dengan tanah dan pupuk kandang $1: 1(\mathrm{v} / \mathrm{v})$, benih biji kopi disemai satu benih setiap polibag dan diletakkan dibawah naungan untuk menghindari sinar matahari langsung. Proses perkecambahan dilakukan selama 6 minggu. Media pembibitan yang digunakan adalah campuran tanah dengan pupuk kandang. Perbandingan komposisi tanah : pupuk kandang sesuai perlakuan yaitu $0,1: 1,1: 2$, 2:1. Tanah dan pupuk kandang yang digunakan terlebih dahulu dibersihkan dari kotoran, kemudian dikeringkan. Tanah dan pupuk kandang yang sudah dikeringkan kemudian diayak dengan ayakan ukuran 8 mesh, agar didapatkan ukuran partikel yang seragam. Benih dipindahkan ke polibag pembibitan berukuran $15 \times 20 \mathrm{~cm}$ sesuai dengan perlakuan. Penanaman bibit kopi dimulai pada stadium serdadu 42 HSS dilakukan dengan cara menyeleksi bibit terlebih dahulu, dipilih bibit yang seragam. Lubang tanam dibuat terlebih dahulu, kemudian bibit dipindahkan ke polibag yang lebih besar dan disusun menurut bagan percobaan. Aplikasi pupuk NPK dilakukan sebanyak dua kali yaitu sebanyak $1 / 3$ dosis perlakuan pupuk NPK diberikan pada 1 MST, dan sebanyak 2/3 dosis diberikan pada 5 MST. Pupuk diberikan dengan cara membenamkan pupuk dengan jarak $2 \mathrm{~cm}$ mengelilingi batang.

Pemeliharaan bibit kopi meliputi Penyiraman dilakukan setiap hari selama masa pertumbuhan tanaman, yaitu pada pagi dan sore hari dengan menggunakan gembor. Penyiangan gulma dilakukan apabila 
terdapat pertumbuhan gulma disekitar tanaman dengan cara mencabut menggunakan tangan. Pembongkaran tanaman dilakukan pada umur bibit 90 HST, pembongkaran dilakukan dengan cara membongkar polibag dalam ember berisi air, yang dipindahkan perakaran yang bersih.

Pengamatan yang diamati adalah: tinggi tanaman, jumlah helai daun, diameter batang, berangkasan basah, berangkasan kering dan volume akar dengan rumus:

$$
\text { Volume Akar }=\mathrm{V}_{2}-\mathrm{V}_{1}
$$

Keterangan: $\mathrm{V} 1=$ volume air awal

$$
\mathrm{V} 2 \text { = volume sesudah diisi akar }
$$

\section{III.HASIL DAN PEMBAHASAN}

\subsection{Pengaruh Komposisi Media Tanam}

Hasil uji $F$ pada analisis ragam menunjukkan bahwa perlakuan komposisi media tanam berpengaruh sangat nyata terhadap DB 60 HST dan 90 HST, BBK dan VA, berpengaruh nyata pada parameter DB 30 HST dan BBB, berpengaruh tidak nyata terhadap TB 30, 60 dan 90 HST, JD 30, 60 dan 90 HST.

\begin{tabular}{|c|c|c|c|c|c|}
\hline \multirow{2}{*}{ Parameter } & \multicolumn{4}{|c|}{$\begin{array}{l}\text { Komposisi Media Tanam } \\
\text { (Tanah:Pupuk Kandang) }\end{array}$} & \multirow{2}{*}{$\mathrm{BNJ}_{0,05}$} \\
\hline & $\begin{array}{c}\text { Kontrol } \\
\left(\mathrm{K}_{0}\right)\end{array}$ & $\begin{array}{l}1: 1 \\
\left(\mathrm{~K}_{1}\right)\end{array}$ & $\begin{array}{c}1: 2 \\
\left(\mathrm{~K}_{2}\right)\end{array}$ & $\begin{array}{l}2: 1 \\
\left(\mathrm{~K}_{3}\right)\end{array}$ & \\
\hline \multicolumn{6}{|l|}{ Tinggi Tanaman $(\mathrm{TT})(\mathrm{cm})$} \\
\hline $30 \mathrm{HST}$ & 9,79 & 9,81 & 9,70 & 9,60 & - \\
\hline $60 \mathrm{HST}$ & 11,53 & 11,15 & 11,23 & 11,41 & - \\
\hline $90 \mathrm{HST}$ & 13,39 & 12,97 & 12,86 & 13,42 & - \\
\hline \multicolumn{6}{|l|}{ Jumlah Daun (JD) (helai) } \\
\hline $30 \mathrm{HST}$ & 2,94 & 2,50 & 2,61 & 2,89 & - \\
\hline $60 \mathrm{HST}$ & 5,89 & 5,33 & 5,56 & 5,67 & - \\
\hline 90 HST & 8,83 & 8,56 & 8,44 & 8,94 & - \\
\hline \multicolumn{6}{|l|}{ Diameter Batang (DB) (mm) } \\
\hline $30 \mathrm{HST}$ & $2,01 \mathrm{ab}$ & $2,08 \mathrm{~b}$ & $1,94 a b$ & $1,94 \mathrm{a}$ & 0,13 \\
\hline $60 \mathrm{HST}$ & $2,53 \mathrm{~b}$ & $2,45 a b$ & $2,39 \mathrm{a}$ & $2,51 \mathrm{~b}$ & 0,10 \\
\hline $90 \mathrm{HST}$ & $2,83 \mathrm{bc}$ & $2,67 \mathrm{ab}$ & $2,65 \mathrm{a}$ & $2,95 \mathrm{c}$ & 0,17 \\
\hline Bobot Brangkasan Basah (BBB) (g) & $4,98 \mathrm{~b}$ & $4,26 \mathrm{ab}$ & $3,89 \mathrm{a}$ & $4,99 \mathrm{~b}$ & 1,08 \\
\hline Bobot Brangkasan Kering (BBK) (g) & $0,76 \mathrm{a}$ & $0,66 \mathrm{a}$ & $0,69 \mathrm{a}$ & $1,05 \mathrm{~b}$ & 0,22 \\
\hline Volume Akar (VA) (ml) & $0,69 \mathrm{ab}$ & $0,51 \mathrm{a}$ & $0,57 \mathrm{a}$ & $0,88 \mathrm{~b}$ & 0,18 \\
\hline
\end{tabular}

Tabel 1. Pengaruh komposisi media tanam terhadap pertumbuhan bibit kopi

Keterangan : Angka yang diikuti oleh huruf yang sama pada baris yang sama berbeda tidak nyata berdasarkan uji Beda Nyata Jujur (BNJ) pada taraf $\alpha=0,05$.

Tabel 1 menunjukkan bahwa media tanam terbaik terdapat pada perlakuan komposisi media tanam tanah : pupuk kandang 2:1 $\left(\mathrm{K}_{3}\right)$ yang dijumpai pada parameter DB 90 HST sebesar 2,95 mm, bobot brangkasan basah sebesar 4,99 $\mathrm{g}$, BBK sebesar $1,05 \mathrm{~g}$ dan VA sebesar $0,88 \mathrm{ml}$ dibandingkan dengan perlakuan lainnya. Hal ini diduga pada kondisi media tanam tersebut sifat fisik, kimia dan biologi media tanam berada dalam kondisi yang kondusif bagi pertumbuhan bibit yang diuji. Perbaikan sifat fisik meliputi perbaikan struktur media tanam yang baik yaitu 
komposisi pori makro dan pori mikro yang seimbang dengan adanya penggunaan bahan organik. Keberadaan bahan organik telah menciptakan struktur tanah menjadi remah sehingga kemampuan tanah menampung udara dan air menjadi lebih baik bagi pertumbuhan bibit tanaman kopi.

Pupuk organik juga dapat menstimulir ketersediaan hara bagi tanaman dan memberikan kondisi lingkungan tumbuh di sekitar perakaran yang lebih baik sehingga dapat meningkatkan pertumbuhan tanaman (Nema et al., 2008). Hasil penelitian Khair et al. (2012), menyatakan bahwa pemberian pupuk organik dapat meningkatkan BBB, BBK, akar dan VA bibit kakao. Pengaruh perlakuan bahan organik pupuk kandang sapi pada tanah dapat meningkatkan porositas tanah, aerasi tanah dan kandungan air pada tanah (Wijaya, 2008). Kandungan dalam pupuk kandang sapi adalah bahan organik dan kandungan unsur $\mathrm{N}$ yang cukup besar serta dapat meningkatkan kemampuan mengikat air sehingga potensial jika digunakan untuk meningkatkan kesuburan tanah.

\subsection{Pengaruh Dosis NPK}

Hasil uji $F$ pada analisis ragam menunjukkan bahwa perlakuan dosis NPK berpengaruh sangat nyata terhadap parameter TB 30 HST, BBB dan BBK bibit, namun berpengaruh tidak nyata terhadap $\mathrm{TB}$ 60, 90 HST; JD 30, 60, dan 90 HST; DB 30, 60, 90 HST dan VA.

Tabel 2. Pengaruh dosis NPK terhadap pertumbuhan bibit kopi

\begin{tabular}{|c|c|c|c|c|c|}
\hline \multirow[b]{2}{*}{ Parameter } & \multicolumn{4}{|c|}{ Dosis NPK (g/polibag) } & \multirow[b]{2}{*}{$\mathrm{BNJ}_{0,05}$} \\
\hline & $\begin{array}{c}\text { Kontrol } \\
\left(\mathrm{N}_{0}\right)\end{array}$ & $\begin{array}{c}1 \\
\left(\mathrm{~N}_{1}\right)\end{array}$ & $\begin{array}{c}1,5 \\
\left(\mathrm{~N}_{2}\right)\end{array}$ & $\begin{array}{c}2 \\
\left(\mathrm{~N}_{3}\right)\end{array}$ & \\
\hline \multicolumn{6}{|l|}{ Tinggi Tanaman $(\mathrm{TT})(\mathrm{cm})$} \\
\hline $30 \mathrm{HST}$ & $10,14 b$ & $9,40 \mathrm{a}$ & $9,88 \mathrm{ab}$ & $9,48 \mathrm{a}$ & 0,57 \\
\hline $60 \mathrm{HST}$ & 11,54 & 11,14 & 11,56 & 11,08 & - \\
\hline $90 \mathrm{HST}$ & 13,02 & 13,07 & 13,51 & 13,03 & - \\
\hline \multicolumn{6}{|l|}{ Jumlah Daun (JD) (helai) } \\
\hline $30 \mathrm{HST}$ & 2,94 & 2,56 & 2,67 & 2,78 & - \\
\hline $60 \mathrm{HST}$ & 2,72 & 5,50 & 5,67 & 5,56 & - \\
\hline $90 \mathrm{HST}$ & 8,33 & 8,89 & 8,78 & 8,78 & - \\
\hline \multicolumn{6}{|l|}{ Diameter Batang (DB) (mm) } \\
\hline $30 \mathrm{HST}$ & 2,01 & 1,95 & 2,00 & 2,04 & - \\
\hline $60 \mathrm{HST}$ & 2,50 & 2,43 & 2,50 & 2,45 & - \\
\hline $90 \mathrm{HST}$ & 2,75 & 2,76 & 2,79 & 2,79 & - \\
\hline Bobot Brangkasan Basah (BBB) (g) & $3,60 \mathrm{a}$ & $4,70 \mathrm{ab}$ & $5,05 \mathrm{~b}$ & $4,77 \mathrm{~b}$ & 1,08 \\
\hline Bobot Brangkasan Kering (BBK) (g) & $0,65 \mathrm{a}$ & $0,71 \mathrm{a}$ & $0,85 \mathrm{ab}$ & $0,94 \mathrm{~b}$ & 0,22 \\
\hline Volume Akar (VA) (ml) & 0,69 & 0,52 & 0,57 & 0,88 & - \\
\hline
\end{tabular}

Keterangan : Angka yang diikuti oleh huruf yang sama pada baris yang sama berbeda tidak nyata berdasarkan uji Beda Nyata Jujur (BNJ) pada taraf $\alpha=0,05$.

Tabel 2 menunjukkan bahwa pada parameter TB kopi pada umur 30 HST dosis NPK terbaik adalah kontrol $\left(\mathrm{N}_{0}\right)$ yaitu sebesar 10,14 cm, hal ini diduga karena cadangan makanan yang tersedia dalam kotiledon masih mencukupi untuk pertumbuhan TB kopi sampai 30 HST, sehingga perbedaan tinggi tanaman yang dihasilkan akibat aplikasi pupuk NPK masih belum berbeda secara nyata. Hasil analisis tanah menunjukkan bahwa ketersediaan $\mathrm{P}$ pada media tanam kontrol termasuk katagori 
sangat tinggi yaitu $53,50 \mathrm{mg} / \mathrm{kg}$ sehingga memungkinkan penyerapan $\mathrm{P}$ yang tinggi oleh tanaman.

Dosis NPK 1,5 g/polibag $\left(\mathrm{N}_{2}\right)$ menghasilkan BBB terbesar yaitu 5,05 g. Hal ini sesuai dengan hasil penelitian Minarsih (2013) yang menyatakan bahwa pemberian dosis pupuk NPK $(15: 15: 15)$ sebanyak $1,5 \mathrm{~g} /$ tanaman dapat menghasilkan pertumbuhan bibit kakao terbaik dibandingkan dengan perlakuan dosis NPK 3, 4,5 dan $6 \mathrm{~g} /$ tanaman. Hal ini diduga karena bibit tanaman hanya menyerap unsur hara sesuai dengan kebutuhan. Asumsi ini diperkuat oleh Mayasari (2012) bahwa pemupukan yang berlebihan tidak menghasilkan pertumbuhan yang baik karena unsur hara tidak mampu diserap seluruhnya oleh tanaman.

Dosis NPK 2 g/polibag $\left(\mathrm{N}_{3}\right)$ menghasilkan BBK terbesar yaitu $0,94 \mathrm{~g}$, dosis NPK $2 \mathrm{~g} /$ polibag merupakan dosis optimum yang dapat diserap oleh bibit kopi. semakin besar dosis NPK maka semakin besar BBK. Hal ini diduga karena adanya kandungan unsur $\mathrm{N}, \mathrm{P}$, dan $\mathrm{K}$ masing-masing sebanyak $15 \%$ dan dosis yang diberikan mencukupi untuk pertumbuhan bibit kopi. Nazari et al. (2008) penambahan pupuk NPK majemuk pada tanaman dapat meningkatkan parameter tinggi tanaman, diameter batang dan bobot brangkasan kering tanaman kelapa sawit pada umur 90 HST.

\subsection{Interaksi Antara Perlakuan Komposisi Media Tanam dan Dosis NPK}

Hasil uji $F$ pada analisis ragam menunjukkan bahwa terdapat interaksi sangat nyata antara perlakuan komposisi media tanam dan dosis NPK terhadap parameter DB $30 \mathrm{HST}$ dan BBB. Namun terdapat interaksi nyata antara komposisi media tanam dan dosis NPK terhadap parameter BBK.

Tabel 3. Interaksi antara perlakuan komposisi media tanam dan dosis NPK

\begin{tabular}{|c|c|c|c|c|c|c|c|}
\hline \multirow{7}{*}{$\begin{array}{c}\text { Diameter } \\
\text { Batang (DB) } \\
(\mathrm{mm})\end{array}$} & \multirow{3}{*}{$\begin{array}{c}\text { Komposisi } \\
\text { Media Tanam } \\
\text { Kontrol }\left(\mathrm{K}_{0}\right)\end{array}$} & \multicolumn{6}{|c|}{ Dosis NPK (g/polibag) } \\
\hline & & Kontrol $\left(\mathrm{N}_{0}\right)$ & $1 \mathrm{~g}\left(\mathrm{~N}_{1}\right)$ & \multicolumn{2}{|c|}{$1,5 \mathrm{~g}\left(\mathrm{~N}_{2}\right)$} & \multicolumn{2}{|c|}{$2 \mathrm{~g}\left(\mathrm{~N}_{3}\right)$} \\
\hline & & $2,00 \quad \mathrm{Bb}$ & $1,99 \mathrm{Bb}$ & 1,80 & $\mathrm{Aa}$ & 2,25 & $\mathrm{Cc}$ \\
\hline & $1: 1\left(\mathrm{~K}_{1}\right)$ & $2,15 \quad \mathrm{Ab}$ & $2,06 \mathrm{Ab}$ & 2,09 & $\mathrm{Ab}$ & 2,04 & $\mathrm{Ab}$ \\
\hline & $1: 2\left(\mathrm{~K}_{2}\right)$ & 1,96 Аа & 1,88 Аа & 2,00 & $\mathrm{Ab}$ & 2,04 & $\mathrm{Ab}$ \\
\hline & $2: 1\left(\mathrm{~K}_{3}\right)$ & 1,94 Aa & $1,87 \mathrm{Aa}$ & 2,11 & $\mathrm{Ab}$ & 1,82 & $\mathrm{Aa}$ \\
\hline & $\mathrm{BNJ}_{0,05}$ & & & & & & \\
\hline \multirow{7}{*}{$\begin{array}{c}\text { Bobot } \\
\text { Brangkasan } \\
\text { Basah(BBB) } \\
\text { (g) }\end{array}$} & Komposisi & \multicolumn{6}{|c|}{ Dosis NPK (g/polibag) } \\
\hline & Media Tanam & Kontrol $\left(\mathrm{N}_{0}\right)$ & $1 \mathrm{~g}\left(\mathrm{~N}_{1}\right)$ & \multicolumn{2}{|c|}{$1.5 \mathrm{~g}\left(\mathrm{~N}_{2}\right)$} & \multicolumn{2}{|c|}{$2 \mathrm{~g}\left(\mathrm{~N}_{3}\right)$} \\
\hline & Kontrol $\left(\mathrm{K}_{0}\right)$ & 2,79 Aa & $5,56 \mathrm{Bb}$ & 5,41 & $\mathrm{Bb}$ & 6,17 & $\mathrm{Bb}$ \\
\hline & $1: 1\left(\mathrm{~K}_{1}\right)$ & $4,01 \quad \mathrm{Aa}$ & 3,50 Aa & 4,16 & $\begin{array}{l}\mathrm{ABa} \\
\mathrm{b}\end{array}$ & 5,36 & $\mathrm{Bb}$ \\
\hline & $1: 2\left(\mathrm{~K}_{2}\right)$ & 3,99 Aa & $4,08 \mathrm{Aa}$ & 3,85 & Aa & 3,65 & $\mathrm{Aa}$ \\
\hline & $2: 1\left(\mathrm{~K}_{3}\right)$ & 3,60 Aa & $5,66 \mathrm{Bb}$ & 6,77 & $\mathrm{Bc}$ & 3,91 & $\mathrm{Aa}$ \\
\hline & $\mathrm{BNJ}_{0,05}$ & \multicolumn{6}{|c|}{1,28} \\
\hline & Komposisi & \multicolumn{6}{|c|}{ Dosis NPK (g/polibag) } \\
\hline Bobot & Media Tanam & Kontrol $\left(\mathrm{N}_{0}\right)$ & $1 \mathrm{~g}\left(\mathrm{~N}_{1}\right)$ & \multicolumn{2}{|c|}{$1.5 \mathrm{~g}\left(\mathrm{~N}_{2}\right)$} & \multicolumn{2}{|c|}{$2 \mathrm{~g}\left(\mathrm{~N}_{3}\right)$} \\
\hline Brangkasan & Kontrol $\left(\mathrm{K}_{0}\right)$ & 0,39 Aa & $0,80 \quad \mathrm{Bbc}$ & 0,80 & $\mathrm{Ba}$ & 1,06 & $\mathrm{Cb}$ \\
\hline Kering (BBK) & $1: 1\left(\mathrm{~K}_{1}\right)$ & $0,70 \quad \mathrm{ABb}$ & $0,47 \quad$ Aa & 0,77 & $\mathrm{Ba}$ & 0.70 & $\mathrm{ABa}$ \\
\hline
\end{tabular}




\begin{tabular}{|c|c|c|c|c|c|c|c|c|c|}
\hline \multirow[t]{2}{*}{ (g) } & $\begin{array}{l}1: 2\left(\mathrm{~K}_{2}\right) \\
2: 1\left(\mathrm{~K}_{3}\right)\end{array}$ & $\begin{array}{l}0,76 \\
0,74\end{array}$ & $\begin{array}{l}\mathrm{Ab} \\
\mathrm{Ab}\end{array}$ & $\begin{array}{l}0,63 \\
0,96\end{array}$ & $\begin{array}{l}\text { Aab } \\
\text { Ac }\end{array}$ & $\begin{array}{l}0,60 \\
1,25\end{array}$ & $\begin{array}{l}\mathrm{Aa} \\
\mathrm{Bb}\end{array}$ & $\begin{array}{l}0.75 \\
1.24\end{array}$ & $\begin{array}{l}\mathrm{Aa} \\
\mathrm{Bb}\end{array}$ \\
\hline & $\mathrm{BNJ}_{0,05}$ & \multicolumn{8}{|c|}{0,26} \\
\hline
\end{tabular}

Keterangan : Angka yang dikuti oleh huruf yang sama (huruf besar menurut baris dan huruf kecil menurut kolom) berbeda tidak nyata berdasarkan uji Beda Nyata Jujur (BNJ) pada taraf uji 0,05.

Tabel 3 menunjukkan bahwa terdapat interaksi yang nyata antara perlakuan komposisi media tanam dan dosis NPK terhadap pertumbuhan bibit kopi yaitu DB pada umur 30 HST, BBB dan BBK pada parameter diameter batang. Diameter batang terbesar dijumpai pada komposisi media tanam kontrol $\left(\mathrm{K}_{0}\right)$ dengan dosis NPK 2 g/polibag $\left(\mathrm{N}_{3}\right)$. Hal ini diduga penggunaan pupuk NPK dengan dosis $2 \mathrm{~g} /$ polibag dapat mendukung pertumbuhan vegetatif bibit kopi lebih baik dibandingkan dengan dosis lainnya. Mamanto (2005) menyatakan bahwa untuk dapat merangsang pertumbuhan tanaman dan diameter batang serta pertumbuhan akar maksimal dapat menunjang berdirinya tanaman yang kokoh dapat dilkakukan dengan pemberian pupuk NPK majemuk pada tanaman.

Pada parameter BBB dan BBK nilai terbaik dijumpai pada perlakuan komposisi media tanam tanah dan pupuk kandang 2:1 $\left(\mathrm{K}_{3}\right)$ dengan dosis NPK 1,5 g/polibag $\left(\mathrm{N}_{2}\right)$. Hal ini diduga akibat adanya kombinasi penggunaan bahan organik dan dosis NPK yang sesuai untuk pertumbuhan bibit kopi. Media tanam yang mengandung bahan organik pupuk kandang sapi 2:1 memiliki porositas tanah lebih baik dibandingkan dengan perlakuan media tanam lainnya semakin baik tingkat porositas dan daya serap air pada media maka pertumbuhan bibit kopi semakin optimal. Bahan organik dapat membantu penyerapan unsur hara dan memperbaiki struktur tanah lebih baik. Hal ini sesuai dengan hasil penelitian Prawoto (2008) juga menunjukkan adanya kecenderungan pertumbuhn bibit tanaman kopi dan kakao terbaik menggunakan media tanam dengan perbandingan tanah dan pupuk kandang 2:1.

Menurut Sudarto et al. (2003) pemberian pupuk kandang sapi pada media tanam dapat memberikan keuntungan bagi pertumbuhan tanaman dan juga meningkatkan kemampuan tanah untuk menyerap air yang berfungsi untuk mineralisasi bahan organik agar dapat dimanfaatkan langsung oleh tanaman.

Pemberian dosis NPK dalam jumlah yang sesuai diduga mampu meningkatkan pertumbuhan bibit kopi, hal ini sesuai dengan pendapat Mamanto (2005) menyatakan bahwa untuk dapat merangsang pertumbuhan tanaman diperlukan penambahan pupuk NPK pada tanaman. Minarsih (2013) yang menyatakan bahwa pemberian dosis pupuk NPK (15:15:15) sebanyak 1,5 g/tanaman dapat menghasilkan pertumbuhan bibit kakao terbaik dibandingkan dengan perlakuan dosis NPK lainnya.

\section{KESIMPULAN}

1. Perlakuan komposisi media tanam berpengaruh sangat nyata pada parameter diameter batang 60, $90 \mathrm{HST}$, bobot brangkasan kering dan volume akar serta berpengaruh nyata pada parameter diameter batang 30 HST dan bobot brangkasan basah. Pertumbuhan bibit kopi terbaik dijumpai pada komposisi media tanam tanah dan pupuk kandang 2:1.

2. Perlakuan dosis NPK berpengaruh sangat nyata terhadap parameter tinggi 
bibit 30 HST, bobot brangkasan basah dan bobot brangkasan kering. Pertumbuhan bibit kopi lebih baik dijumpai pada dosis NPK 1,5 g/polibag.

3. Terdapat interaksi yang sangat nyata antara komposisi media tanam dan dosis NPK terhadap parameter diameter batang 30 HST dan bobot brangkasan basah serta berpengaruh nyata terhadap parameter bobot brangkasan kering. Pertumbuhan bibit kopi terbaik dijumpai pada kombinasi komposisi media tanam 2:1 dengan dosis NPK 1,5 g/polibag.

\section{DAFTAR PUSTAKA}

Dewantara, F. R., J. Ginting dan Irsal. 2017. Respon pertumbuhan bibit kopi robusta (Coffea robusta L.) terhadap berbagai media tanam dan pupuk organik cair. Jurnal agroteknologi FP USU. 5(3): 676684.

Ding, T., S. Hery dan A. Patah. 2015. Pengaruh berat benih dan media tanam terhadap pertumbuhan vegetatif bibit (Durio zibethinus Murr.). Jurnal AGRIFOR. 8 (16): 261-268.

Ditjenbun. 2015-2017. Percepatan perluasan dan peremajaan tanaman kopi. http://www.ditjenbun.pertanian.go.i d. Diaskes tanggal 24 Januari 2018.

Handayani, F., Mastur dan Nurbani. 2011. Respon dua varietas kedelai terhadap penambahan beberapa jenis bahan organik. Prosiding Semiloka Nasional Dukungan Agro-Inovasi untuk Pemberdayaan Petani. BPTP Jawa Tengah, Jawa Tengah.
Khair, S. M. Z.dan Karno. 2012. Pengaruh Pupuk Organik terhadap Pertumbuhan dan Produksi Kopi Arabika, Jurnal Agrivigor. 6(1):8592.

Lingga, P. dan Marsono. 2001. Petunjuk Penggunaan Pupuk. Penebar Swadaya, Jakarta.

Mamanto, R. 2005. Pengaruh penggunaan dosis pupuk majemuk NPK Phonska terhadap pertumbuhan dan produksi jagung manis (Zea mays Saccharata slurt). [Skripsi]. Fakultas Pertanian Universitas Icshan, Gorontalo.

Mayasari, P. Pemilihan teknologi dalam rangka optimasi pengelolaan perkebunan kopi. Warta Pusat Penelitian Kopi dan Kakao. 14(1): 16-22.

Minarsih, M. A. Syamsul, A. Maria, V. R. dan Rasdi, E. 2013. Pengaruh pemberian kompos kulit buah kakao sebagai campuran media tanam pembibitan dan pupuk NPK $(15: 15: 15)$ terhadap pertumbuhan bibit kakao Theobroma cacao $L$. Jurnal Agrotek Tropika. 2: 189194.

Nazari, Y. A. 2008. Respon pertumbuhan bibit kelapa sawit (Elais guineensis Jacq) pada pembibitan kelapa sawit. Majalah Ilmiah Pertanian, 23 (3): 170-184.

Nema, Rusli, Sakiroh dan E. Wardiana. 2008. Pengaruh pemupukan terhadap pertumbuhan, hasil dan kualitas biji empat klon kopi robusta di tanah podsolik merah kuning, Lampung Utara. J. TIDP. 2(2): 107-112 
Pertiwi, I. dan Ardian. 2013. Pemberian pupuk vermikompos pada bibit kopi robusta. Departement of Agrotecnology, Faculty of Agricultur, Riuan University. 8:1-2.

Prawoto, A. A. 2008. Panduan Lengkap Kakao : Manajemen Agribisnis dari Hulu Himgga Hilir. Penebar Swadaya. Jakarta.

Prayugo, S. 2007. Media Tanam untuk Tanaman Hias. Penebar Swadaya. Jakarta.

Rahardjo, P. 2013. Panduan Budi Daya dan Pengolahan Kopi Arabika dan Robusta.Penerbar Swadaya, Jakarta.

Simorangkir, J. W., J. Ginting dan Irsal. 2016. Respon pertumbuhan bibit kakao (Thebroma cacao L) terhadap beberapa komposisi media tanam dan frekuensi penyiraman. Jurnal Agroteknologi FP USU. (632):2324-2330.

Sudarto, M. Zairin, A. Hipi dan A. Surahman. 2003. Pengaruh jenis dan dosis pupuk kandang terhadap pertumbuhan dan produksi jagung manis (Zea mays saccharata Sturt). Pastura. (1): 2-5.

Sutejo, M. M. 2002. Pupuk dan Cara Penggunaan. Jakarta : Rineka Cipta.

Wijaya, K. A. 2008. Nutrisi Tanaman. Prestasi Pustaka. Jakarta. 115 hlm. 